\title{
Autonomia docente e formação continuada de professores para o ensino de ciências investigativo com uso do laptop educacional.
}

\author{
Dirce Cristiane Camilotti ${ }^{1}$, Shirley Takeco Gobara ${ }^{2}$ \\ ${ }^{1}$ Faculdade de Educação - Programa de Pós-Graduação em Educação - Doutorado em \\ Educação - Universidade Federal de Mato Grosso do Sul (UFMS). \\ ${ }^{2}$ Instituto de Física - Universidade Federal de Mato Grosso do Sul (UFMS) \\ dcamilotti@gmail.com, stgobara@gmail.com
}

\begin{abstract}
This article analyzes the development of teacher autonomy in a research-training for use of the educational laptop in the research teaching of sciences, based on Contreras. It is a qualitative research in which the diagnostic and final interviews with four teachers were analyzed. The analyzes showed that the pedagogical practice of the teachers before the training was characteristic of a technical specialist/illusory autonomy. Post-formation, in the practice of the teachers appear characteristic elements of a reflexive autonomy and emancipatory autonomy. Such autonomy was facilitated by the democratic and open characteristic of research-training
\end{abstract}

Resumo. Este artigo analisa o desenvolvimento da autonomia docente em uma pesquisa-formação para uso do laptop educacional no ensino investigativo de ciências, com base em Contreras. Trata-se de uma pesquisa qualitativa em que foram analisadas as entrevistas diagnósticas e finais realizadas com quatro professoras. As análises evidenciaram que a prática pedagógica das professoras antes da formação era característica de um profissional especialista técnico/autonomia ilusória. Pós-formação, na prática das professoras aparecem elementos característicos de uma autonomia reflexiva e autonomia emancipatória. Tal autonomia foi facilitada pela característica democrática e aberta da pesquisa-formação.

\section{Introdução}

O uso pedagógico dos recursos tecnológicos, dentre eles os laptops educacionais, ao serem integrados ao desenvolvimento do conteúdo curricular favorecem professores e alunos para inserção no mundo digital, mais comunicacional e interativo, contribuindo na construção de novos conhecimentos pelos alunos. Para que seu uso signifique melhorias na prática pedagógica do professor e nas atividades pedagógicas, é necessário que sejam integradas ao currículo escolar por meio de propostas inovadoras (Almeida e Valente, 2011). Tais inovações, entretanto, deverão ser integrada à prática pedagógica de forma contextualizada e contribuir para a autonomia do professor para uso desses recursos tecnológicos. Esses aspectos devem estar presentes na formação de professores para o uso das Tecnologias Digitais de Informação e Comunicação (TDIC).

O desenvolvimento da autonomia do professor para uso da TDIC no ensino de ciências vai além da apropriação dos recursos tecnológicos pelo professor e compreende 
VI Congresso Brasileiro de Informática na Educação (CBIE 2017)

Anais do XXIII Workshop de Informática na Escola (WIE 2017)

dimensões de sua profissionalidade. Segundo Contreras (2002), a obrigação moral, compromisso com a comunidade e competência profissional estão voltados para a formação de alunos críticos, capazes de intervir e modificar seu contexto social numa perspectiva emancipatória.

As pesquisas realizadas após a implantação do Programa um Computador por Aluno (PROUCA), fase II, nas escolas públicas de Mato Grosso do Sul, evidenciaram que a formação continuada de professores realizada não foi suficiente para provocar mudanças na prática pedagógica deles (Gobara et. al., 2014; Camilotti e Gobara, 2016). Com base nesses resultados, foi realizada uma pesquisa-formação para investigar o uso do laptop educacional voltado ao ensino de ciências na educação infantil e nos anos iniciais do ensino fundamental, pois uma das hipóteses para o insucesso na formação do PROUCA é que esta foi realizada desvinculada de uma proposta metodológica adequada às diferentes áreas do conhecimento.

O presente trabalho é um recorte dessa pesquisa-formação e teve como objetivo analisar o desenvolvimento da autonomia das professoras participantes, na perspectiva da autonomia docente descrita por Contreras (2002), para uso do laptop educacional associado à proposta do ensino investigativo de ciências (Carvalho e Gil Perez, 2011).

\subsection{Referencial teórico: autonomia do professor para uso das TDIC no ensino de ciências investigativo.}

No mundo contemporâneo, é constante o surgimento de novas informações em uma sociedade em que o conhecimento científico e tecnológico estão cada vez mais presentes e necessários para o exercício da cidadania. O ensino de ciências deve voltarse para a construção de conhecimentos que contribuam para a formação de cidadãos críticos (Carvalho, 2013). Esse cenário exige mudança na prática do professor com inovações didático-pedagógicas que facilitem os processos de ensino e aprendizagem e o cumprimento do papel da escola (Libâneo, 2007).

Segundo Carvalho e Gil-Pérez (2011), a formação inicial e continuada de professores de ciências devem estimular o questionamento do senso comum, a visão simplista da ciência e do trabalho científico e a maneira repetitiva e acrítica com que é abordada na escola. Portanto, na sociedade atual há a necessidade de um ensino de ciências que vá além da transmissão dos conceitos científicos e propicie aos alunos não somente noções e conceitos, mas também coloque-os diante de problemas autênticos (Carvalho, 2013), tal qual sugere o ensino investigativo.

Nesta mesma perspectiva, Alonso (2008) chama atenção para o reducionismo no entendimento sobre as TDIC usado na formação docente, para a necessidade de debater sobre as bases desta profissão e sobre a constituição da instituição escolar. As ideias da autora, condizentes com as ideias de Contreras (2002), reside no fato de que a inserção das TDIC, propostas nas formações continuadas, foca no domínio técnico dos métodos e uso das tecnologias.

Isto significa que a formação do professor de ciências não deve ser descontextualizada da realidade global, para que ele possa ensinar ciências com vistas à formação de cidadãos críticos, alfabetizados cientificamente e digitalmente. Neste sentido, Gimeno e Sacristán (2006) trazem à reflexão o problema do distanciamento entre a prática do pesquisador formador e dos professores, referentes à pesquisa e à elaboração das formações. Essa pode ser uma explicação, segundo os autores, para muitos dos programas de formação continuada serem implantados sem critérios bem definidos e não alterarem a prática pedagógica. Outro problema importante a ser considerado é que o professor de ciências da educação infantil e anos iniciais do Ensino 
VI Congresso Brasileiro de Informática na Educação (CBIE 2017)

Anais do XXIII Workshop de Informática na Escola (WIE 2017)

Fundamental é um profissional formado em Pedagogia, que conclui a sua formação inicial, geralmente, sem estar preparado para ensinar ciências (Soares et al., 2013 apud Camilotti e Gobara, 2016).

Nesse sentido, as ideias de Contreras (2002) têm muito a contribuir com o processo de formação continuada que possibilite a atuação do professor para um ensino de ciências com qualidade, numa visão coletiva e emancipatória. Esse autor discute a autonomia sobre o enfoque da profissionalidade docente, relacionando-a com os diferentes modelos de professores: especialista técnico, profissional reflexivo e intelectual crítico. A autonomia profissional é definida como qualidade profissional e/ou como qualidade educativa, construída numa perspectiva de defesa dos valores profissionais a partir da análise da natureza educativa do trabalho docente e não pelas estratégias da profissionalização (Contreras, 2002). Assim, a autonomia deve ser entendida como a capacidade do homem, na sua dimensão individual e social, de agir conscientemente por si e para si, na intenção de garantir as necessidades e o bem-estar individual e coletivos a partir de relações de cooperação e reciprocidade que vão além das relações de subordinação e submissão. Professores autônomos têm a capacidade de reflexão crítica nos momentos de formação e de atuação profissional. Esta autonomia será desenvolvida a partir da superação da racionalidade técnica em um processo de defesa de valores considerados profissionais.

$\mathrm{Na}$ perspectiva da autonomia profissional, Contreras (2002) aponta três dimensões da profissionalidade do professor: a obrigação moral, o compromisso com a comunidade e a competência profissional. A obrigação moral para com o ensino e com os alunos a partir da consciência do que é desejável educativamente e de que toda ação docente tem consequência moral. O compromisso com a comunidade reconhecendo que a escola prepara para a vida e que a educação envolve a participação da comunidade no ensino. Na dimensão da competência profissional, estão envolvidos o domínio de habilidades, técnicas e recursos para a ação didática, conhecimentos do objeto que se ensina. Neste quadro teórico, o conceito de autonomia é descrito a partir de três modelos epistemológicos de racionalidade pedagógica que se associam a um modelo de professor: a racionalidade técnica associada ao especialista técnico; a racionalidade prática relacionada ao profissional reflexivo e a racionalidade crítica associada ao intelectual crítico.

O professor autônomo, então, segundo Libâneo (2007) é aquele capaz de pensar e refletir sobre a sua prática, planejando e executando o seu trabalho e construindo um novo modelo de trabalho intelectual a serviço da transformação social. Para isto, deve romper com a prática de mero transmissor e executor para a de um profissional consciente de seu papel social, que reflete sobre a coletividade, planeja e executa as suas ações. Tal ruptura está associada à formação continuada de professores que traga à escola um projeto democrático, com participação dos envolvidos nas decisões e que compreenda as questões pedagógicas contextualizadas à profissão docente.

\section{Método: pesquisa-formação para uso pedagógico do laptop educacional no ensino de ciências investigativo.}

A formação de professores para uso do laptop educacional no ensino de ciências, na educação infantil e nos anos iniciais do ensino fundamental, proposta no âmbito da pesquisa-formação, foi desenvolvida durante dois anos, com carga horária de 120 horas por ano. A pesquisa-formação caracteriza-se por aproximar os polos da pesquisa e da formação, em que a pesquisa "regula" a formação e a formação oferece suporte à pesquisa (Vosgerau, 2012). Assim, o conjunto de conteúdos e estratégias da ação e na 
ação docente surge dos problemas, temas e necessidades do grupo. Aspectos que apontam um diferencial relevante da proposta de formação implementada: priorizou-se as necessidades dos participantes a partir da investigação das dificuldades dos professores, que foram levantadas no contexto de uma das etapas da pesquisaformação, e, após, desenvolveu-se a formação levando-se em conta as dificuldades e necessidades observadas ao longo da formação.

Inicialmente, participaram da formação 18 professoras de uma escola pública no interior do Mato Grosso do Sul, sendo que no segundo ano, até o final dela, permaneceram oito participantes. No primeiro ano, foram desenvolvidos a etapa diagnóstica, a fim de conhecer o perfil das participantes, e três módulos da formação. No segundo ano, foram realizados mais três módulos.

As formações foram realizadas à distância, na modalidade semipresencial, desenvolvida no contexto escolar e planejada a partir das necessidades das participantes, observadas no diagnóstico, durante os encontros presenciais do grupo e nos momentos de interação online. Os principais temas discutidos nestes momentos foram a apropriação tecnológica e uso pedagógico do laptop, o ensino de ciências investigativo na educação infantil e anos iniciais, as concepções espontâneas e científicas no ensino de ciências, saberes docentes, a alfabetização científica, o planejamento e desenvolvimento de sequências investigativas, temas específicos de conteúdos da ciência. Nos encontros presenciais, foram realizadas: a) discussões sobre teorias, metodologias e recursos para uso do laptop educacional no ensino de ciências, b) oficinas sobre os aplicativos do laptop e conteúdos de ciências, c) avaliações e autoavaliações (Camilotti e Gobara, 2016).

Este artigo é um recorte dessa pesquisa-formação, pesquisa de cunho qualitativa (Ludke e André, 1986) em que foi realizada uma análise exploratória das entrevistas realizadas com quatro professoras que concluíram a formação. Foram analisadas as entrevistas diagnósticas e as entrevistas finais, realizadas antes do início da formação e no final dela. Dessa forma, os sujeitos da pesquisa foram as quatro professoras da educação infantil e anos iniciais, doravante identificadas como PA, PB, PC e PD.

Foram entrevistas semiestruturadas, individuais e gravadas. A entrevista diagnóstica teve o objetivo de conhecer o perfil das participantes a partir do seu processo de formação continuada, apropriação das ferramentas do laptop educacional e sua prática pedagógica com uso deste recurso no ensino de ciências. A entrevista final teve a intenção de verificar aspectos relacionados à apropriação tecnológica do laptop educacional e à prática pedagógica das professoras no ensino de ciências após a participação na formação.

A análise das entrevistas foi realizada por meio da comparação das informações obtidas antes e depois da formação para observar o desenvolvimento da autonomia das professoras no uso pedagógico do laptop educacional para o ensino de ciências investigativo, na perspectiva da autonomia docente e com base nos modelos de professor descritos por Contreras (2002). Para fins de comparação foram estabelecidas as seguintes categorias: prática pedagógica no ensino de ciências, uso pedagógico do laptop e uso da metodologia de ensino investigativo.

\section{Resultados e discussão}

As quatro professoras participantes da entrevista são professoras da Pré-Escola ou dos anos iniciais do Ensino Fundamental, somente uma não é pedagoga e uma possui especialização. O tempo de uso do computador pelas professoras variou de 03 a 05 
anos, exceto pela PB que utiliza a mais tempo. As professoras PA e PD trabalham com a disciplina de ciências, a PC ministra as aulas de artes para as turmas do pré ao $5^{\circ}$ ano, a PB é formada em letras e ministra as aulas de informática (Tabela 1). Na pesquisaformação o uso do laptop educacional nas aulas de ciências foi trabalhado numa perspectiva multidisciplinar, em que a professora de artes (PC) e informática (PB) planejaram e desenvolveram sequências de ensino investigativo (SEI) que integraram os conteúdos de ciências às suas respectivas disciplinas.

$\begin{gathered}\text { Tabela 1. Perfil das professoras } \\
\text { tecnologias). }\end{gathered}$
\begin{tabular}{|c|c|c|c|c|c|}
\hline Prof. & Idade & $\begin{array}{c}\text { Formação Inicial/ } \\
\text { Especialização }\end{array}$ & $\begin{array}{c}\text { Ano em que atua } \\
\text { como professora }\end{array}$ & $\begin{array}{c}\text { Tempo de } \\
\text { Serviço }\end{array}$ & $\begin{array}{c}\text { Tempo de uso do } \\
\text { computador }\end{array}$ \\
\hline PA & 39 & $\begin{array}{c}\text { Pedagogia/Ed. Especial } \\
\text { e Infantil }\end{array}$ & Pré-Escola I & 20 & 03 \\
\hline PB & 21 & Letras & $\begin{array}{c}\text { Informática: } \\
\text { Pré ao 5 }\end{array}$ & 03 & 08 \\
\hline PC & 48 & Pedagoga e Arte & Arte: Pré ao 5 & 11 & 03 \\
\hline PD & 36 & Pedagogia e Letras & $5^{\circ}$ & 15 & 05 \\
\hline
\end{tabular}

A análise das entrevistas diagnósticas evidenciou que todas as professoras já utilizavam o computador antes do PROUCA ser implantado na escola (Tabela 1) e que também utilizavam o laptop em suas aulas uma vez por semana. O laptop era usado com os alunos para digitação de palavras e pequenos textos, jogos educativos offline e online, pesquisas na internet de textos e imagens e atividades complementares ao conteúdo como cruzadinhas, quebra-cabeças e questionários. Essa forma de uso evidencia que a prática das professoras tem características tradicionais e instrucionistas, centrada na proposição de exercícios e uso dos recursos do laptop para buscar informações prontas e jogar sem a proposição de um acompanhamento dos erros ou avaliação contínua do desempenho dos alunos (Goabara et. al., 2014).

Esse diagnóstico é reforçado por Gomes e Grandra (2010) que chamam atenção de que o uso do computador em sala de aula apenas para o reforço de atividades e para atrair a atenção dos alunos leva à automatização do que se faz convencionalmente e a subutilização dos inúmeros recursos de comunicação, interação e acesso à informação disponível. Isso demonstra que antes da formação o laptop era utilizado como um apêndice nas atividades pedagógicas, sem integração com o conteúdo curricular. Nessa perspectiva, o uso das tecnologias tem como base apenas o domínio técnico, sem a inserção de novas metodologias que levassem à construção do conhecimento para formação do aluno crítico e consciente da sua realizada social, o que caracteriza uma autonomia ilusória do professor (Contreras, 2002). Nesse contexto, a prática pedagógica é dependente de diretrizes técnicas e há certa incapacidade de resposta do professor diante de situações didáticas incertas.

Ainda nesta perspectiva, a prática do professor está baseada na racionalidade técnica no modelo do professor especialista técnico, em que o domínio técnico dos recursos tecnológicos é usado para alcançar resultados previstos em uma prática que separa concepção e execução das ações pedagógicas. Contreras (2002), enfatiza a necessidade de uma requalificação para a racionalização da prática em uma perspectiva crítica. Entendemos que a formação continuada para uso das tecnologias digitais que alia uma metodologia investigativa ao domínio técnico dos recursos é a base para o desenvolvimento de uma autonomia baseada na racionalidade crítica.

As análises das entrevistas finais (Quadros 1 e 2) evidenciaram que após a participação na pesquisa-formação houve mudança no uso pedagógico do laptop. 
VI Congresso Brasileiro de Informática na Educação (CBIE 2017)

Anais do XXIII Workshop de Informática na Escola (WIE 2017)

As professores passaram a utilizá-lo com mais frequência e em atividades voltadas para a produção dos alunos, como construção de tabelas e gráficos, câmera para registro, produção de textos, de slides e uso de simuladores. Somente a PD continuou a utilizar o laptop apenas para acesso de informação pelos alunos, sobretudo para leitura de textos e assistir vídeos.

Quadro 1. Prática pedagógica das professoras PA e PB após a participação da pesquisaformação.

\begin{tabular}{|c|c|c|c|}
\hline Prof. & $\begin{array}{l}\text { Prática pedagógica no ensino de ciências } \\
\text { após a formação. }\end{array}$ & $\begin{array}{l}\text { Uso pedagógico do } \\
\text { laptop após a } \\
\text { formação }\end{array}$ & $\begin{array}{l}\text { Uso da metodologia de } \\
\text { ensino investigativo após } \\
\text { a formação. }\end{array}$ \\
\hline PA & $\begin{array}{l}\text { - Conscientização sobre a necessidade de } \\
\text { construção do conhecimento pelo aluno e o } \\
\text { conhecimento de uma metodologia } \\
\text { investigativa. } \\
\text { - Começou a buscar o conhecimento dos } \\
\text { conceitos científicos. } \\
\text { - Aprendeu conceitos científicos que não } \\
\text { havia aprendido na graduação. } \\
\text {-Mudança do conceito de como a criança } \\
\text { aprende. } \\
\text {-Aprendeu a "tentar" confrontar o } \\
\text { conhecimento empírico com o científico. } \\
\text {-Conseguiria trabalhar dentro do ensino } \\
\text { investigativo (mesmo tendo dificuldade com } \\
\text { as etapas da SEI). } \\
\text {-Reconhecimento do papel do professor na } \\
\text { alfabetização digital das crianças, mesmo nas } \\
\text { aulas de ciências. } \\
\text { - Reconhecimento da importância da } \\
\text { aprendizagem dos conceitos de ciências a } \\
\text { formação de alunos críticos. }\end{array}$ & $\begin{array}{l}\text { - Uso das ferramentas } \\
\text { do Libre Office, } \\
\text { mesmo sem internet. } \\
\text { - Uso de simuladores } \\
\text { para observar os } \\
\text { fenômenos. } \\
\text {-Uso do laptop na SEI } \\
\text { integrado a outras } \\
\text { tecnologias (lousa } \\
\text { digital, projetor e livro } \\
\text { didático). } \\
\text {-Usa com mais } \\
\text { frequência (uma a } \\
\text { duas vezes por } \\
\text { semana). } \\
\text { - Uso para construção } \\
\text { de tabela e gráfico. } \\
\text {-Uso da câmera para } \\
\text { registro. }\end{array}$ & $\begin{array}{l}\text {-Mesmo não } \\
\text { desenvolvendo uma SEI } \\
\text { inteira, mudou a prática } \\
\text { pedagógica adequando } \\
\text { algumas atividades em } \\
\text { sala de aula com } \\
\text { características } \\
\text { investigativas. } \\
\text { - Mudou a forma de } \\
\text { iniciar a aula: faz } \\
\text { perguntas para os alunos } \\
\text { sobre o tema para } \\
\text { identificar o que eles já } \\
\text { sabem. } \\
\text { - Propõe problemas. } \\
\text { - Discute os problemas } \\
\text { locais (ambiente, política, } \\
\text { saúde, por exemplo). }\end{array}$ \\
\hline PB & $\begin{array}{l}\text { - Passou a usar o laptop nas aulas de ciências, } \\
\text { pois percebeu as possibilidades do uso. } \\
\text { - Percebeu que é possível trabalhar ciências } \\
\text { em todas as disciplinas. } \\
\text { - Sente-se segura para usar o laptop no } \\
\text { desenvolvimento de uma SEI. } \\
\text {-Reconhece a importância da valorização do } \\
\text { conhecimento empírico do aluno. } \\
\text { - Uso do laptop fora da sala em atividades } \\
\text { das aulas. }\end{array}$ & $\begin{array}{l}\text {-Produção de textos e } \\
\text { construção de } \\
\text { gráficos. } \\
\text { - Consegue planejar } \\
\text { atividades com uso do } \\
\text { laptop e não apenas } \\
\text { jogos. } \\
\text { - Uso do laptop com } \\
\text { mais frequência (uma } \\
\text { vez por semana ou } \\
\text { quinzenalmente). }\end{array}$ & $\begin{array}{l}\text { - Uso em atividades de } \\
\text { pesquisa e resolução de } \\
\text { problemas. } \\
\text { - Usa nas aulas de } \\
\text { ciências e língua } \\
\text { portuguesa com perguntas } \\
\text { problematizadoras e } \\
\text { valorização do } \\
\text { conhecimento empírico } \\
\text { do aluno,mas não chegou } \\
\text { a desenvolver uma SEI. }\end{array}$ \\
\hline
\end{tabular}

Tais atividades, com participação ativa dos alunos produzindo a informação em um contexto de investigação, podem ser caracterizadas como construcionistas (Valente, 2005) com o aluno realizando uma produção com uso do laptop de forma a construir o seu conhecimento na realização da espiral da aprendizagem. Nesse cenário, observa-se a integração do laptop ao currículo escolar visto que atividades como as citadas pelas professoras PA, PB e PC (Quadros 1 e 2) podem auxiliar o aluno a construir o conhecimento, adotando como principal eixo articulador de suas atividades a busca de respostas a questões que têm significado para a própria vida e contexto dos aprendizes (Almeida e Valente, 2012). 
Sobre a prática pedagógica no ensino de ciências, na entrevista diagnóstica as quatro professoras afirmaram que nunca utilizaram o laptop nas aulas de ciências e nem os computadores da sala de informática. Quando questionadas sobre as aulas de ciências sem o uso destes recursos as professoras citaram como práticas corriqueiras aulas expositivas, o uso do livro didático, demonstrações e exercícios de fixação. Afirmaram que não utilizavam o laptop porque têm dificuldades em planejar atividades com os conteúdos de ciências e avaliaram que a aprendizagem adquirida na formação inicial foi superficial e focada apenas no uso de livros didáticos, com textos e exercícios de fixação. Após a pesquisa-formação, as entrevistas finais evidenciaram mudança significativa na prática pedagógica no ensino de ciências (Quadro 1 e 2), não apenas no uso do laptop, mas também na metodologia utilizada.

Quadro 2. Prática pedagógica das professoras PC e PD após a participação da pesquisaformação.

\begin{tabular}{|c|c|c|c|}
\hline Prof. & $\begin{array}{l}\text { Prática pedagógica no ensino de ciências } \\
\text { após a formação. }\end{array}$ & $\begin{array}{l}\text { Uso pedagógico do } \\
\text { laptop após a } \\
\text { formação }\end{array}$ & $\begin{array}{c}\text { Uso da metodologia de } \\
\text { ensino investigativo após } \\
\text { a formação. }\end{array}$ \\
\hline $\mathrm{PC}$ & $\begin{array}{l}\text {-Aprendeu conceitos importantes de ciências } \\
\text { (citou os conceitos científicos trabalhados } \\
\text { nas oficinas). } \\
\text { - Passou a trabalhar os conteúdos de ciências } \\
\text { nas aulas de artes. } \\
\text {-Aprendeu a deixar os alunos darem } \\
\text { respostas. } \\
\text {-Usou conceitos científicos para justificar o } \\
\text { "lanche saudável" exigido na escola. }\end{array}$ & $\begin{array}{l}\text {-Uso da planilha para } \\
\text { organização de dados } \\
\text { com as crianças. } \\
\text { - Uso do editor de } \\
\text { texto e de } \\
\text { apresentação para } \\
\text { produção de texto e } \\
\text { slides. }\end{array}$ & $\begin{array}{l}\text {-Não desenvolveu a SEI } \\
\text { em todas as etapas, mas } \\
\text { usa procedimentos da } \\
\text { metodologia investigativa } \\
\text { em sua prática: perguntar } \\
\text { e ouvir os alunos para ver } \\
\text { o que é relevante para eles } \\
\text { dentro de determinado } \\
\text { conteúdo, propor } \\
\text { atividades com problemas } \\
\text { para eles buscarem a } \\
\text { informação e não dar } \\
\text { respostas prontas. }\end{array}$ \\
\hline PD & $\begin{array}{l}\text {-Aprendizagem de conceitos específicos de } \\
\text { ciências. } \\
\text {-Viu a amplitude do que ainda precisa } \\
\text { aprender para ensinar ciências. } \\
\text { - Visualizou as possibilidades de ensinar } \\
\text { ciências na prática, em uma investigação. } \\
\text {-Mudou sua concepção sobre o ensino de } \\
\text { ciências e reconhece a importância da } \\
\text { participação ativada do aluno nas aulas de } \\
\text { ciências. }\end{array}$ & $\begin{array}{l}\text {-Usa o laptop para } \\
\text { leitura de textos e } \\
\text { assistir vídeos. }\end{array}$ & $\begin{array}{l}\text {-Reflete sobre o que } \\
\text { poderia fazer em sala de } \\
\text { aula a partir da } \\
\text { metodologia da formação. } \\
\text { - Não se sente preparada } \\
\text { para desenvolver todas as } \\
\text { etapas da SEI. }\end{array}$ \\
\hline
\end{tabular}

Nas suas práticas após a formação, as professoras citaram elementos característicos de um ensino de ciências investigativo, como a valorização do conhecimento prévio e empírico do aluno, atividades que levam os alunos a confrontarem o conhecimento empírico com o científico, a importância da construção do conhecimento pelo aluno, a importância e papel do professor na alfabetização científica e digital dos alunos. A metodologia da SEI, usada na pesquisa-formação, atende a essas características do ensino investigativo e pode iniciar o aluno no processo de alfabetização científica (Carvalho, 2013). Esta ação requer a superação da prática pedagógica baseada na transmissão do conhecimento (Carvalho e Gil-Pérerz, 2011).

As mudanças relatadas pelas professoras em suas práticas pedagógicas evidenciam indícios da superação da visão simplista do ensino de ciências manifestadas no início da formação. Elas também manifestaram a necessidade de buscar aprimorar $o$ conhecimento científico para que o aluno e o professor possam se posicionar 
criticamente diante das questões da sociedade atual de acordo com Carvalho e Gil-Pérez (2011). Estes indícios são evidenciados no relato da PA que reconheceu a importância da aprendizagem dos conceitos de ciências para a formação de alunos críticos. As quatro professoras citaram também a aprendizagem de conceitos científicos, e reconheceram a necessidade de aprofundar esses conhecimentos e a possibilidade de trabalhá-los de forma multidisciplinar. Contreras (2002) destaca o reconhecimento do papel do conhecimento para a sua formação e a formação de alunos capazes de superar as distorções ideológicas. A obrigação moral para com o ensino e com os alunos, 0 compromisso com a comunidade e a competência profissional são dimensões da profissionalidade do professor que estão presentes no relato das professoras.

Estes são elementos importantes a serem trabalhados nas formações continuadas do pedagogo para ensinar ciências, visto que em sua formação inicial nem sempre aborda-se satisfatoriamente o conteúdo de ciências (Camilotti e Gobara, 2016).

Ao serem questionadas sobre o uso da metodologia de ensino investigativo, após a formação continuada, as professoras PA, PB e PC afirmaram que não desenvolveram uma SEI, em todas as suas etapas, após a formação. No entanto, relatam que incorporaram alguns elementos do ensino investigativo nas aulas de ciências, como: perguntas para se conhecer o conhecimento empírico dos alunos; perguntar e ouvir os alunos para ver o que é relevante para eles dentro de determinado conteúdo; proposição de problemas que leve à pesquisa das informações e não dar respostas prontas aos questionamentos dos alunos. Somente a PD relatou que não alterou a sua prática, pois não se sente preparada para planejar e desenvolver atividades com características investigativas.

As análises das entrevistas evidenciam que as ações formativas realizadas no âmbito da pesquisa-formação proporcionaram o desenvolvimento de atitudes por parte das professoras (quadro 1) que são indícios de que elas estão adquirindo a autonomia desejada segundo Contreras (2002). Antes da formação a prática pedagógica das professoras apresentava caraterísticas do profissional especialista técnico, descrito por Contreras, com uma autonomia ilusória e incapacidade de respostas diante da incerteza. Após a formação, observamos que as professoras PB e PC apresentaram em suas práticas elementos característicos do professor profissional reflexivo com autonomia individual para resolver situações e problemas para realização prática dos objetivos educativos. A PA, após a formação, ao citar a importância do ensino de ciências para a formação de um aluno crítico e ao trazer a discussão sobre os problemas locais, apresentou elementos característicos do profissional intelectual crítico e indícios de uma autonomia como emancipação. A professora PD, embora tenha citado a aprendizagem para uso do laptop e metodologia investigativa, ela ainda apresentou características de um especialista técnico, evidenciando que as ações formativas não foram suficientes para que ela pudesse superar a racionalidade técnica associada ao processo de desprofissionalização a que foi subordinada ao longo de sua experiência como docente.

Vale ressaltar que na formação analisada o desenvolvimento da autonomia descrita por Contreras (2002) é um processo lento e transitório que ocorre com a superação do profissional especialista técnico, passa pelo professor reflexivo, até o desenvolvimento da autonomia emancipatório, própria do profissional intelectual crítico.

\section{Conclusões}

As análises evidenciaram que as ações desenvolvidas na pesquisa-formação provocaram um rompimento da prática do especialista técnico e a superação da 
racionalidade técnica de três professoras. A prática pedagógica das professoras $\mathrm{PB}$ e PC, após a formação, sugere o desenvolvimento de uma autonomia reflexiva a partir da racionalidade prática, enquanto na prática da PA já são observados indícios de uma autonomia emancipatória. Somente a PD não traz em sua prática pós-formação características de superação da racionalidade técnica. Vale ressaltar que, para o desenvolvimento da autonomia docente, para um ensino de ciências emancipatório, $o$ contexto formativo deve resgatar a base reflexiva da atuação profissional a partir da racionalidade prática e levar o professor a compreender o contexto social e ter consciência do seu trabalho numa ação crítica.

A formação do pedagogo como profissional intelectual crítico, no contexto do uso das TDIC no ensino de ciências investigativo, deve caracterizar-se pela articulação dos conhecimentos teóricos com a prática, a reflexão, e a superação da racionalidade técnica, além da compreensão das dimensões da obrigação moral, do compromisso com a comunidade e competência profissional. Estes elementos devem ter como base uma visão coletiva do trabalho docente, do ensino de ciências e suas implicações sociais. Além disso, deve ir além da discussão de conhecimentos técnicos dos recursos didáticos e considerar os conhecimentos específicos de ciências e metodologias investigativas articuladas com reflexões que levem ao reconhecimento do contexto trabalhista, institucional e social em que os professores realizam seu trabalho, bem como a ideologia que o determina.

Tais discussões devem ser intencionais e devem promover o desenvolvimento da análise e crítica social na ação política transformadora. Embora, o cenário formativo estabelecido na pesquisa-formação realizada tenha permitido a participação ativa dos professores, as dificuldades apresentadas pelas professoras para articular 0 conhecimento científico com a metodologia investigativa e o uso das tecnologias possibilitou uma reflexão para que as mesmas pudessem questionar a formação inicial caracterizada pela prática do especialista técnico e pela autonomia ilusória, baseadas nos pressupostos da racionalidade técnica, porém não foi possível a contextualização das questões inerentes à proletarização do professor. Esses aspectos serão objetos de investigação de uma outra pesquisa que está em curso.

\section{Referências bibliográficas}

Almeida, M. E. B. e Valente, J. A. (2012). "Integração currículo e tecnologias e a produção de narrativas digitais". Currículo sem Fronteiras, Volume12, Número 3, 57-82.

Almeida, M. E. B. e Valente, J. A. (2011). “Tecnologias e Currículo: trajetórias convergentes ou divergentes?" São Paulo: Paulus.

Alonso, K. M. (2008). "Tecnologias da informação e comunicação e formação de professores: sobre rede e escolas". Educação e Sociedade, Volume 12, Número $104,748-768$.

Camilotti, D. C.; Gobara, S. T. "Uso do laptop educacional em sequências de ensino investigativas para o ensino de ciências na educação infantil e anos iniciais". In: Anais do IV Congresso Internacional TIC e Educação, Lisboa, Portugal. p. 1556-1568.

Carvalho, A. M. P. (2013). "O ensino de Ciências e a proposição de sequências de ensino investigativas." In: A. M. P. Carvalho (Org.), Ensino de Ciências por investigação: condições para implementação em sala de aula. São Paulo: Cengage Learning. 1-20. 
VI Congresso Brasileiro de Informática na Educação (CBIE 2017)

Anais do XXIII Workshop de Informática na Escola (WIE 2017)

Carvalho, A. M. P. e Gil-Pérez, D. (2011). "Formação de professores de Ciências: tendências e inovações". Coleção Questões da nossa época. São Paulo: Cortez, 2011.

Contreras, J. (2002). “A autonomia de professores”. São Paulo: Cortez.

Gimeno Sacristán, J. (2006). "Tendências investigativas na formação de professores". In: Pimenta, S. G. (org.). (2006). Professor Reflexivo no Brasil: gênese e crítica de um conceito. São Paulo: Cortez, p. 81-87.

Gobara, S. T.; Camilotti, D. C.; Avancini, R. "Perfil dos Professores Participantes de uma Pesquisa-Formação para o Uso Pedagógico do Laptop Educacional no Ensino de Ciências das Séries Iniciais e Educação Infantil". In: Anais do $3^{\circ}$ Congresso Brasileiro de Informática na Educação, Dourados, MS. p. 840-842.

Gomes, M. A. F e Gandra, A. F. (2010). "Letramento Digital dos Professores dos Anos Iniciais do Ensino Fundamental". In: Anais do WIE - XVI Workshop Sobre Informática na Escola, Belo Horizonte, MG.

Libâneo, J. C. (2007). "Pedagogia e pedagogos, para quê?” São Paulo: Cortez.

Ludke, M. e André, M. (1986). "Pesquisa em educação: abordagens qualitativas". São Paulo: EPU.

Valente, J. A (2005). "A Espiral da Espiral de Aprendizagem: o processo de compreensão do papel das tecnologias de informação e comunicação na educação". Tese (Livre Docência). Universidade Estadual de Campinas (UNICAMP).Vosgerau, D. S. R. (2012). A pesquisa ação-formação como instrumento de formação em serviço para integração das TIC na prática pedagógica do professor. Formação Docente, v. 4, n. 7, p. 51-64. 